\title{
Reuni e seus impactos nas Instituições Federais de Educação Superior (IFES): uma análise da admissão de docentes de 2007 a 2017
}

\author{
Reuni and its impacts on Federal Institutions of Higher Education (IFES): an \\ analysis of professor's admissions from 2007 to 2017
}

Reuni y sus impactos en las Instituciones Federales de Educación Superior (IFES): una análisis de la admisión de profesores de 2007 a 2017

\author{
ROBERTO DE SOUZA SALLES \\ ORCID iD: http://orcid.org/0000-0002-1482-1585 \\ Universidade Federal Fluminense - Rio de Janeiro. \\ EDUARDO FAERSTEIN \\ ORCID iD: http://orcid.org/0000-0002-4027-4896 \\ Universidade Estadual do Rio de Janeiro - Instituto de Medicina Social. \\ MARIO ROBERTO DAL POZ \\ ORCID iD: http://orcid.org/0000-0002-3005-3280 \\ Universidade Estadual do Rio de Janeiro - Instituto de Medicina Social. \\ PABLO SILVA MACHADO BISPO DOS SANTOS \\ ORCID iD: http://orcid.org/0000-0002-1582-8519 \\ Universidade Federal Fluminense - Rio de Janeiro.
}

\begin{abstract}
Resumen: O artigo analisa impactos do Programa de Apoio a Planos de Reestruturação e Expansão das Universidades Federais (Reuni) na educação superior brasileira, usando como principal indicador a admissão de docentes concursados nas Instituições Federais de Ensino Superior (IFES). Foram analisados os dados oficiais do censo da educação superior dos anos de duração do programa, traçando um paralelo com a literatura publicada sobre o tema. O estudo aborda instituições de todas as regiões do país, com vistas a correlacionar o indicador escolhido com o desenvolvimento das diretrizes do programa.
\end{abstract}

Palabras-clave: Educação Superior. Reuni. Análise de impacto. Docentes.

Resumo: This article analyzes the impact of the Support Program for the Restructuring and Expansion of Federal Universities (Reuni) in the Brazilian higher education, using as the major performance indicator the admission of teachers in the Federal Institutions of Higher Education (IFES). For this purpose, official data of the census of higher education of the years of the duration of the program have been analyzed, establishing a correlation with the published literature related to this subject. Institutions from all regions of the country are addressed in the study, to correlate the chosen indicator with the development of the program guidelines.

Palavras-chave: Higher Education. Reuni. Impact analysis. Faculty. 
Abstract: El articulo analiza el impacto del Programa de Apoyo a Planes de Reestructuración y Expansión de las Universidades Federales (Reuni) en la educación superior brasileña, utilizando como indicador principal el ingreso de docentes en las Instituciones Federales de Educación Superior (IFES). Analizamos los datos oficiales del censo de educación superior de los años de duración del programa, haciendo un paralelo con la literatura publicada sobre el tema. El estudio aborda instituciones de todas las regiones del país, con el fin de correlacionar el indicador elegido con el desarrollo de las directrices del programa.

Keywords: Educación universitaria. Reuni. Análisis de impacto. Profesores.

\section{INTRODUÇÃO}

A década de 1990 foi fortemente marcada por uma política educacional de incentivos à criação e à expansão de universidades, centros universitários e faculdades do setor privado. A justificativa era de que a crise no setor da educação se devia ao mau gerenciamento dos recursos públicos (DOURADO, 2002).

Outra marca dessa década foi a quebra do modelo universitário baseado no tripé ensino-pesquisa-extensão e a diferenciação das instituições federais de ensino superior (IFES), classificadas na Lei $n^{\circ}$ 9.394/1996 (LDB) em universidades, centros universitários, faculdades isoladas, faculdades integradas e institutos superiores de educação.

A partir de 2003, a partir do início do primeiro mandato do Governo Lula, o Brasil iniciou o processo de construção de políticas que preconizavam a concentração de esforços na resolução de questões prioritárias para o País, as quais incluíam a educação superior como elemento imprescindível ao projeto de democratização do ensino (DOURADO, 2003).

Em termos políticos, seguindo a linha-mestra do Programa de Aceleração do Crescimento (PAC), o Ministério da Educação (MEC) idealizou um programa com o objetivo de criação de condições de ampliação do acesso e permanência na educação superior, melhorando o aproveitamento da estrutura física e dos recursos humanos existentes, além da ampliação do número de alunos das IFES. Tal programa foi denominado Programa de Apoio a Planos de Reestruturação e Expansão das Universidades Federais - REUNI e instituído pelo Decreto 6.096/07 (Brasil, 2007-b).

Os indicadores relativos aos anos de 2007 a 2017 (BRASIL, 2018) apontam para um crescimento de matrículas da ordem de 63,9\%, o que, em números absolutos, significa a entrada de mais 834.758 estudantes nas IFES, considerando um total de 1.306.351 estudantes. Se for considerado somente o período referente à vigência do Reuni (2007 a 2013), os dados indicam que o crescimento do número de matrículas expressa o acréscimo de 42,4\%, ou seja, 553.893 novos estudantes nas IFES durante o período supracitado. 
O expressivo acréscimo no número de matrículas das IFES na década de 2007 a 2017 chama a atenção devido à concentração dessas coincidir temporalmente com a implantação e vigência do Reuni, razão pela qual buscamos examinar mais detidamente outro indicador que se correlaciona ao número de estudantes: o número de docentes. Assim, uma pergunta que foi ponto de partida na investigação apresentada neste artigo é: houve nas IFES um aumento do número de docentes correlato à expansão do número de estudantes?

O presente estudo tem por objetivo uma análise dos impactos do Reuni, buscando mapear (ao menos em parte) impactos no ensino, pesquisa e extensão das IFES. Nesse sentido, entendemos ser fundamental tomar como indicador principal a admissão de docentes através de concursos públicos ${ }^{1}$ nas IFES.

No nível jurídico-político, cabe asseverar que a elaboração do Reuni não foi um ato isolado. O programa é parte de outros marcos regulatórios, a exemplo da Lei $n^{\circ}$ 10.172/2001, que instituiu o Plano Nacional da Educação (PNE), com duração decenal (2001-2010), e que procurou tanto diagnosticar a situação educacional quanto propor diretrizes que orientariam os objetivos e metas a serem cumpridas no prazo de uma década para cada um dos níveis e modalidades de educação/ensino. Além disso, o conjunto de ações que integraram o Plano de Desenvolvimento da Educação - PDE (BRASIL, 2007-a), instituído pelo Decreto $n^{\circ}$ 6.094/2007, possuía como um dos seus eixos a expansão da educação superior (principalmente no que se refere ao sistema federal de educação). Tal programa consistiu em política pública que fomentou ações em colaboração entre os entes federados visando a melhoria da qualidade educacional. No que se refere à educação superior, pode-se dizer que: "O Reuni compôs uma das ações do Plano de Desenvolvimento da Educação (PDE), somatório de vários programas instituídos por decretos" (CAMPOS; CARVALHO, 2015, p. 6). Tais ações deram ensejo ao desenvolvimento da educação superior pública, seja buscando ampliar o acesso com o aporte a iniciativas como a Universidade Aberta do Brasil (UAB), ou a partir de ações de reestruturação administrativa e financeira, como o caso do Reuni, objeto de estudo neste artigo.

Para Antunes (2016), as diretrizes gerais do Reuni definiram "expansão" como uma ampliação do acesso, por meio do aumento das matrículas em cursos de graduação presenciais nas universidades, e a democratização relacionada à

1 A opção por focar a análise nos docentes concursados se dá pelo fato de que, em havendo expansão, os concursados se incorporam aos quadros das IFES, caracterizando assim uma política pública de reestruturação que vai para além do período de validade do Reuni, o que a caracterizaria como um indicador da construção de uma Política de Estado, indo para além do mandato governamental referente à condução da mesma. 
inclusão social, no sentido de minimizar desigualdades e proporcionar a grupos que historicamente sofreram por falta de oportunidades o acesso ao ensino superior público, diversificando assim o ambiente universitário brasileiro.

Em relação à delimitação temporal do artigo ora apresentado, deve ser ressaltado que os dados analisados se referem ao período de implantação e execução do Reuni (2007-2013), porém considerando que os impactos do programa se desdobraram por alguns anos após seu encerramento em 2013. Para efeito de comparação e melhor entendimento, a análise inclui (complementarmente) os dados advindos do censo da educação superior do Instituto Nacional de Estudos e Pesquisas Educacionais Anísio Teixeira (INEP) registrados até o ano de 2017 (BRASIL. INEP, 2017). Em suma: muito embora a duração do Reuni tenha ocorrido entre 2007 e 2013, a periodização deste trabalho abrange os anos que vão de 2007 a 2017.

Nossa hipótese principal é a de que correlata à ampliação quantitativa dos quadros de docentes, houve melhorias na educação superior brasileira, sobretudo no que tange à ampliação ao acesso ingresso de estudantes neste nível do ensino.

Ainda sobre a análise efetuada, o artigo apresenta um exame do impacto desta política pública em relação ao processo de absorção de novos docentes ao quadro, de maneira a reduzir certa lacuna teórica a respeito desta dimensão do Reuni e mapear as características de implementação em nível nacional desta política educacional a partir de uma análise regional, de maneira a explicitar semelhanças, desigualdades, costumes e especificidades.

O campo empírico foi delimitado de forma a selecionar de três a quatro instituições para cada região do país, a fim de mapear estes impactos de forma abrangente e utilizando como critério o número de alunos e de docentes dessas IFES.

\section{CONTEXTO HISTÓRICO-POLÍTICO DA EDUCAÇÃO SUPERIOR NA IMPLANTAÇÃO DO REUNI}

Em 2007 o Brasil contava com 2.281 instituições de ensino superior (IES), sendo $89 \%$ delas privadas e apenas 11\% públicas. Segundo Antunes (2016), as matrículas totais somavam 4.880 .381 alunos de graduação presencial, dividindose em 74,6\% nas instituições privadas e $25,4 \%$ nas públicas, e representando algo em torno de $11 \%$ dos jovens na faixa etária entre 18 e 24 anos - o que configuraria um ensino ainda elitista e excludente, privilégio para poucos. Já os índices de conclusão atingiam, em números brutos, isto é, somando a graduação presencial e educação a distância, apenas 756.799 dos alunos. 
Com a mudança do cenário político, de 2003 a 2014 foram aprovadas diversas ações de modernização e reconfiguração do estado no Brasil, sobretudo no que diz respeito às áreas de educação e assistência social. No que compete à educação superior, o mote principal foi a reestruturação das universidades brasileiras, o que foi levado a cabo considerando três dimensões centrais a esta política pública instituinte (SANTOS, 2014)²: avaliação, autonomia e financiamento.

Naquele período surgiu a lei de inovação tecnológica, o sistema nacional de avaliação da educação superior (Sinaes), além do decreto das fundações, dos contratos de gestão, da autonomia financeira das IFES, e, ainda, a implantação da educação a distância (EAD), o Reuni, o Programa Universidade para Todos (Prouni) e o Financiamento Estudantil do Ensino Superior (FIES).

Em relação aos programas supracitados, o Prouni e o Reuni estariam inseridos no quadro das políticas públicas relacionadas à democratização do acesso à educação superior. O objetivo do Prouni era a concessão de bolsas de estudos integrais e parciais em cursos de graduação e sequenciais de formação específica em IES privadas de educação superior, enquanto o Reuni teria sido criado para promover a expansão do acesso à educação superior pública, visando melhor aproveitamento da estrutura física e dos recursos humanos existentes nas universidades, bem como a possibilidade de incrementar as condições de permanência discente na educação superior.

Conforme Costa et al. (2013), é nas IFES que se concentram o maior número de pesquisadores e, consequentemente, de pesquisas, em que se possui o corpo docente mais qualificado, com sua maioria composta de doutores, e, portanto, são estas instituições que oferecem o ensino de melhor qualidade no país. O Reuni vinha como um programa que proporcionaria o crescimento das IFES aproveitando melhor todo esse potencial intelectual disponível.

Souza et al. (2015) desenvolveram uma pesquisa ampla no tocante ao dimensionamento desse crescimento, fazendo um detalhamento da criação de universidades federais entre os anos de 2003 e 2012, examinando o número de professores efetivos, substitutos e visitantes além de analisar a produção científica na Web of Science, entre outras variáveis. Uma das conclusões desse estudo apontou para um crescimento global do número de docentes, principalmente do quadro permanente das instituições que apresentaram um aumento estimado em $44 \%$, observando neste período um salto no número de docentes efetivos e redução de, aproximadamente, $64 \%$ de professores substitutos, além do aumento de $22 \%$ de professores visitantes, conforme o gráfico a seguir:

2 De acordo com Santos: “[...]existem as Políticas Públicas instituintes, que determinam o regime político, a forma do Estado e a maneira como este se apresenta composto (2014, p. 11)”. 


\section{Gráfico 1 - Crescimento do número de professores nas IFES.}

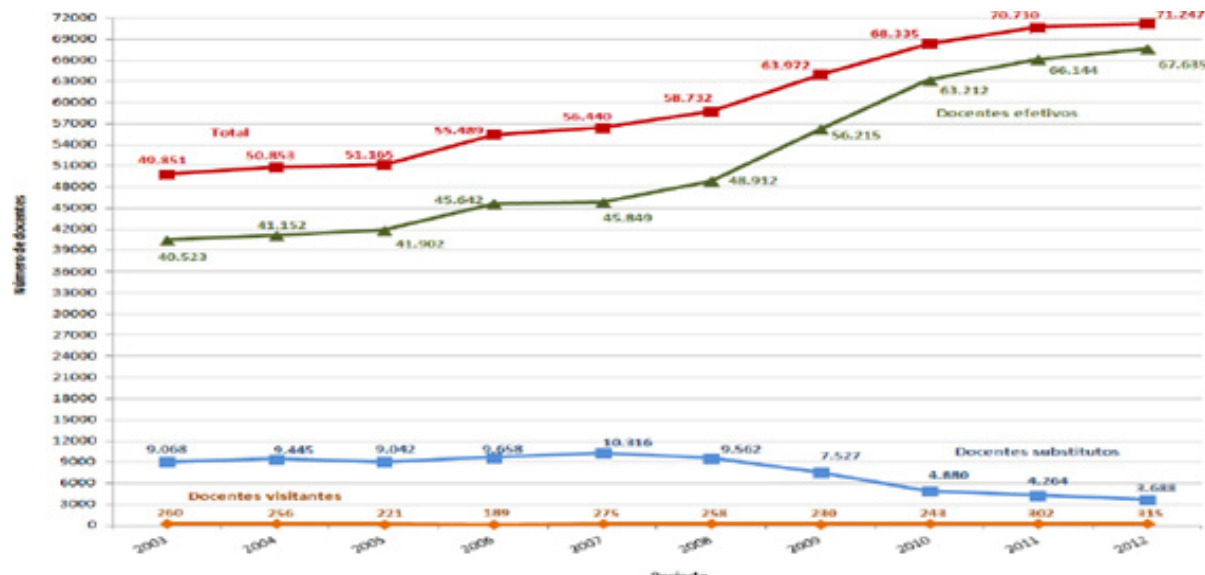

Fonte: Souza et al. (2015)

Há uma corrente que aponta no sentido contrário, de que houve uma precarização das instituições, que teriam sido transformadas em "escolão" e a atividade docente estaria sofrendo com isso. Maués (2010) indicou uma reconfiguração do trabalho docente em decorrência do Reuni, o que se daria a partir do impacto "produtivista" do programa:

Nessa 'cultura da produtividade' o trabalho do professor entra na exploração capitalista, mas existem outros fatores que caracterizam a precarização do trabalho docente no tocante ao ensino, à pesquisa e à extensão. $\mathrm{O}$ número de alunos em sala de aula na graduação é um desses aspectos. Na determinação do Programa de Apoio a Planos de Reestruturação e Expansão das Universidades Federais (Reuni, Dec. 6.096/07), ao qual todas as universidades federais aderiram, a exigência de 18 alunos por professor é um dos fatores que vai contribuir para o fato. A expansão da ordem de $100 \%$ no número de ingressantes e de $200 \%$ no das matrículas, também como item desse mesmo programa, pode levar a universidade a uma expansão sem o correspondente aumento do número de vagas para professores, no afã de receber verbas que não ultrapassam $10 \%$ a $20 \%$ do que atualmente é destinado às IFES. (...) A situação de precarização, de intensificação do trabalho docente vem ocasionando sofrimento nos sujeitos envolvidos que se sentem pressionados de forma objetiva e subjetiva para aderirem a esse modelo de Universidade mercantilizada. (Maués, 2010, p. 153154). 
Mancebo e Bessa (2009) aludem a certa "heteronomia e precarização" da atividade docente devido ao Reuni, como segue:

A necessidade do cumprimento das metas de expansão propostas no Reuni e os limites orçamentários anteriormente apresentados são, na realidade, as justificativas para essa portaria, que cria um "banco de professoresequivalentes" e uma estratégia de contratação de substitutos. Em síntese, o banco de professores-equivalente corresponde ao total de professores de $3^{\circ}$ grau efetivos e substitutos em exercício na universidade, no dia 31 de dezembro de 2006, expresso na 'unidade professor- equivalente'. (...), todavia, mesmo com as modificações introduzidas na Portaria Interministerial $n^{\circ} 224$, de 23 de julho de 2007, considerando no cálculo a pós-graduação, o banco de professores equivalentes permanece um mecanismo ágil que força um aumento de produtividade institucional, em detrimento da qualidade, necessariamente, resultando na precarização das condições de trabalho. A possibilidade de reposição rápida de professores efetivos por substitutos em maior número vai aprofundar, além disso, o fosso entre o trabalho realizado pelo professor efetivo, com dedicação exclusiva, e o trabalho do professor substituto, cujo contrato de trabalho o limita a dar aulas" (Mancebo; Bessa, 2009. p. 58-59).

Nesse sentido, Costa et al. (2013) esclareceram que o departamento das instituições federais de educação superior (DIFES/SESU/MEC) informou que a meta do Reuni de 18 alunos por professor na graduação era condizente com a meta da Organização para Cooperação e Desenvolvimento Econômico (OCDE), que por sua vez é uma meta mundial.

Além disso, era prioridade do governo federal, como forma de investimentos no ensino, pesquisa e extensão, a articulação para realização de concursos públicos, objetivando aumento do quadro docente nas universidades.

Leher (2012) faz uma crítica no tocante à distribuição dos recursos do Reuni, dizendo que nem os recursos previstos na primeira minuta do decreto para instituir a Universidade Nova e nem o Reuni agregam montantes significativos de recursos ao orçamento geral das IFES, e que os parcos investimentos serão direcionados para a função de "escolão", afirmando que:

O atendimento do Plano de cada IFES é condicionado à capacidade orçamentária e operacional do MEC (Art.3, §3o), o que pode confirmar um montante inferior a 20\%, assim, a hipótese de que as universidades contratem docentes e invistam em infra- estrutura e não recebam os magros recursos adicionais não pode ser descartada. A rigor, com o decreto 6069/07, o MEC não fica obrigado a se responsabilizar com a garantia dos recursos adicionais acordados. Considerando o PAC e o virtual congelamento das despesas correntes da União, essa possibilidade não é pequena. (Leher, 2012, p.14). 
Já Paula (2018) apresenta uma visão positiva, de que o total de docentes doutores e técnicos administrativos atuantes na educação superior cresceu em média 3,12\% e 1,67\% ao ano, respectivamente, e essa alteração da composição docente no decorrer desses 10 anos se deveu às exigências de titulação nos concursos públicos realizados pelas IFES e dos programas de capacitação para professores instituídos pela Capes e CNPq.

Seus estudos apontaram que o índice de qualificação do corpo docente (IQCD) brasileiro, que mensura a qualidade do corpo docente e varia de 1 a 5 com base na titulação, entre 2002 e 2015 foi de 3,89.

Souza et al. (2015) analisaram qualitativamente a titulação dos docentes das universidades federais brasileiras, concluindo que de 2003 a 2012 houve um aumento de $17,83 \%$ no número de professores doutores, reflexo dos investimentos e incentivos à qualificação do corpo docente das IFES.

Partindo para análise de documentos publicados em revistas de alto prestígio no meio acadêmico científico, Souza et al. (2015) apontam que entre os anos de 2003 e 2012 houve um crescimento interanual de 11,31\% do número de publicações brasileiras indexadas na Web of Science, sendo 88\% dessas publicações do sistema de educação superior, sendo as universidades federais as que mais aumentaram sua produção e ganharam mais espaço, subindo de 53\% para 64\% das publicações do sistema universitário.

$\mathrm{Na}$ dimensão da cooperação internacional por meio do ensino, da pesquisa e da extensão, seus reflexos na produção científica foram de significativa importância na distribuição de bolsas implementadas pelo programa ciência sem fronteiras, em especial as de graduação sanduíche no exterior.

Segundo Souza et al. (2015), entre os anos de 2003 e 2012, os programas de mobilidade internacional nas universidades federais brasileiras tiveram como destino, principalmente, os países do grupo dos sete (G7), ou seja, os sete países mais industrializados do mundo e com ampla base de pesquisa.

Todos esses investimentos e esforços promoveram a expansão do sistema universitário brasileiro, garantindo seu espaço na comunidade científica internacional e aumentando a parceria com diversos países e a troca de conhecimento, colaborando significativamente para o avanço da produção científica mundial. 


\section{PANORAMA DA EDUCAÇÃO SUPERIOR NO BRASIL APÓS O REUNI}

Passados seis anos da finalização do Reuni (encerrado em 2013, e considerando o ano de 2019 como marco temporal atual) e levando em consideração as transformações ocorridas nas IFES, se torna necessária uma reanálise do panorama da educação superior brasileira como forma de avaliar a efetividade das políticas educacionais aplicadas e buscar compreender o que ocorreu no âmbito da educação superior.

Inegavelmente houve um salto no número de IES no Brasil desde 2007, com grande destaque para a criação de universidades, centros universitários e institutos federais de educação tecnológica (IFET's) o que fez com que o número de matrículas nas IES públicas e privadas saltasse de 4.880 .381 em 2007 para 8.286.663 em 2017 (INEP, 2017).

Ainda há evidente predominância da iniciativa privada na oferta de educação superior no Brasil, correspondendo a aproximadamente $75 \%$ do número total de matrículas, como mostrado no gráfico 2 .

\section{Gráfico 2 - Alunos matriculados em nível nacional (Rede Pública e Privada).}

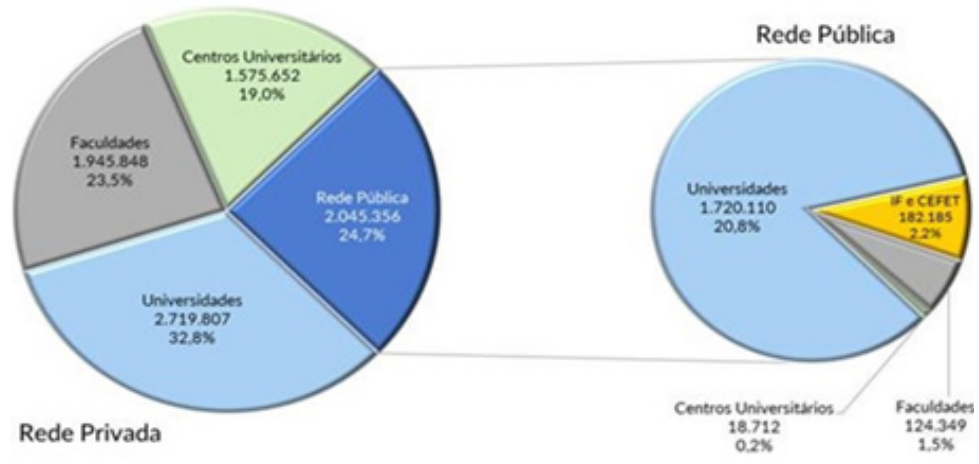

Fonte: MEC/INEP, 2017.

Ao analisarmos detalhadamente a rede pública, percebemos que, apesar do quadro diverso (no tocante aos tipos de IES), as universidades respondem por aproximadamente $80 \%$ do montante de IES públicas, o que implica em outra diretriz no que tange ao planejamento da educação superior em larga escala, o qual apresenta características de maior organicidade e complexidade, como a indissociabilidade do tripé ensino-pesquisa-extensão, característica particular das universidades. 
O estudo demostra que quase metade dos estudantes matriculados na educação superior brasileira não estudam em universidades, realizando seus cursos de graduação em faculdades ou centros universitários, sendo que, ao considerarmos o total dos estudantes presentes em universidades, estes em grande parte se alocam em instituições privadas, que correspondem a 32,8\% do total.

\section{Gráfico 3 - Distribuição das Matrículas na Rede Pública}

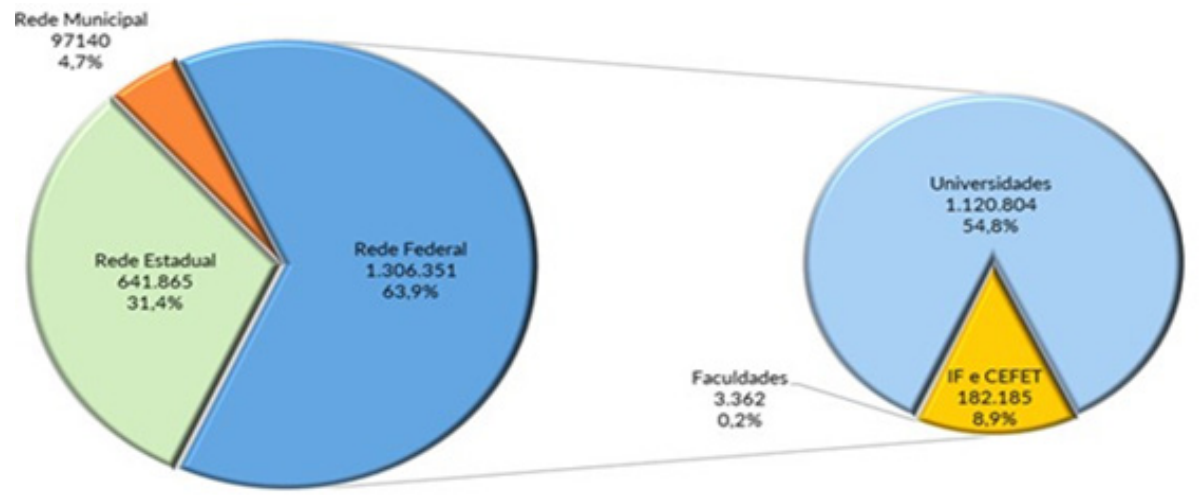

Fonte: MEC/INEP, 2017.

Dentro da rede pública de ensino superior, podemos depreender do gráfico 3 que a rede federal concentra a maioria dos matriculados, respondendo por $63,9 \%$. Cabe salientar que aproximadamente $85 \%$ destes estudam em universidades, enquanto 15\% (182.185) dos matriculados estão concentrados nos IFs e CEFETs.

\section{Gráfico 4 - Distribuição dos concluintes em nível nacional.}

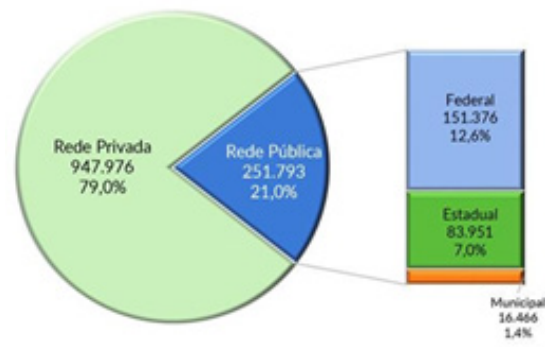

Fonte: MEC/INEP, 2017. 
Usando como indicador o número de concluintes das graduações, confirma-se a tendência majoritária da iniciativa privada. Conforme se depreende do gráfico 4, apenas um em cada cinco alunos concluiu sua graduação em uma IES da rede pública. E, ao analisarmos esses concluintes da rede pública, notase que $60 \%$ concluíram sua graduação em uma IES federal, enquanto 33,3\% o fizeram em uma instituição da rede estadual e aproximadamente $7 \%$ concluíram seu curso de graduação em uma IES municipal.

Abaixo apresentaremos uma sequência de dados de cinco IFES durante o período de 2007 a 2017 e que tiveram a maior oferta de vagas nos cursos de graduação (nas modalidades: presencial e EAD).

\section{Gráfico 5 - IFES com maior oferta de vagas de 2007 a 2017.}

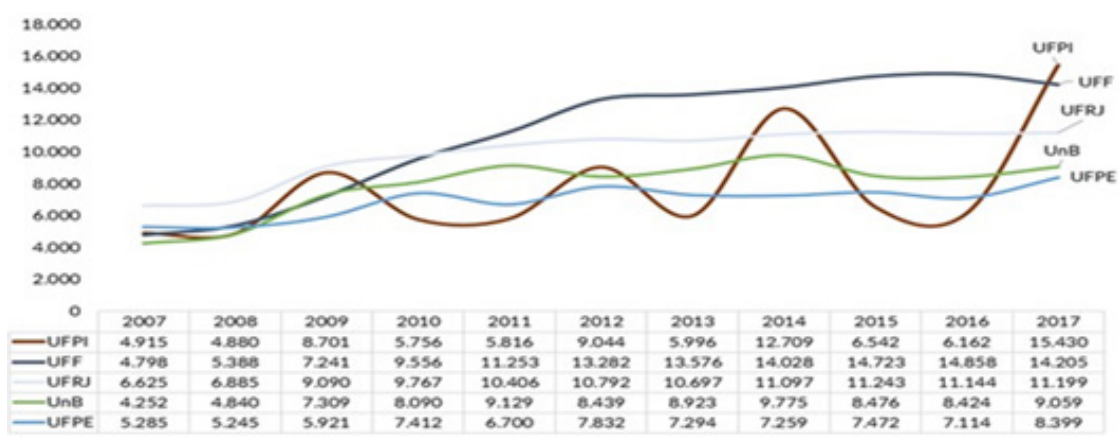

Fonte: MEC/INEP, 2017.

A partir destes dados é possível compreender de forma mais aprofundada a expansão do número de vagas oferecidas pelas cinco IFES com maiores scores deste indicador durante o período abrangido pelo estudo.

Iniciando o estudo pelos dados da UFPI, temos no início da série histórica 4.915 vagas ofertadas contra 15.430 ao fim da série histórica, o que representa um incremento de 10.515 vagas (em termos percentuais temos uma variação de $136,28 \%$ ). Esta variação, porém, apresenta uma irregularidade (retração de vagas e aumentos bruscos em seu quantitativo) em diversos momentos. Tomemos como exemplo o número de vagas da UFPI nos anos de 2012 (9.044) e 2013 (5996). Isto indica certa "sazonalidade" nos cursos ofertados por esta Universidade.

Em relação à UFF, há no ano de 2007 a oferta de 4.798 vagas. Já e em 2017, a UFF ofereceu 14.205 vagas, o que indica que neste período houve uma expansão de vagas da ordem de 132,54\% (em números absolutos: mais 9407 vagas). Durante toda a série histórica, o número de vagas segue uma expansão constante, à exceção do ano de 2017, cujo número de vagas é menor do que 
em 2016. Merece destaque o período entre 2008 a 2011, no qual a oferta de vagas se amplia em 5.865 vagas ou $91,86 \%$. Neste sentido, subentende-se que para a UFF o período relativo ao Reuni trouxe grande expansão de vagas para esta Universidade, as quais continuam a se ampliar nos quatro anos subsequentes ao encerramento do Programa.

A UFRJ, por sua vez, ofereceu 6.625 vagas no ano de 2007 e, ao fim da série, em 2017, 11.199 vagas. Em números absolutos este quantitativo corresponde ao incremento de 4.574 vagas, ou, em termos percentuais, $81,68 \%$ a mais de vagas. A variação nos números da UFRJ também apresenta uma ampliação crescente e constante durante os dez anos (de 2007 a 2017) abrangidos pelo estudo. Merece destaque, porém, o intervalo entre 2008 e 2009 (sob a vigência do Reuni), quando este número vai de 6.885 (em 2008) a 9.095 (em 2009), o que representa, em termos percentuais uma expansão de $32 \%$ do número de vagas em um ano.

Os dados relativos ao número de matrículas da UnB expressam uma expansão no número de vagas ao longo dos dez anos da série histórica, indo de 4.252 vagas em 2007 a 9.059 em 2017, o que implica numa ampliação percentual da ordem de $53 \%$ ao longo da série histórica. Durante os anos de 2008 e 2009, a UnB experimentou o maior aumento no número de vagas oferecidas, variando (em números absolutos) de 4.840 em 2008 a 7.309 em 2009 (uma variação percentual de 51,01\% do número de vagas). Mais uma vez, cabe indicar que esta é uma tendência que, assim como observado nas demais IFES, indica expansão de vagas durante o Reuni.

Em relação à oferta de vagas na UFPE, entre 2007 e 2017, temos os seguintes dados: 5.285 vagas em 2007 e 8.399 em 2017, o que implica em uma variação percentual da ordem $58,9 \%$ durante toda a série histórica. Ao analisar como estas vagas se distribuem, é possível observar que nos anos de 2009 e 2010 ocorre a maior variação no sentido de ampliar o número de vagas, as quais vão de 5.921 (em 2009) a 7.412 (em 2010), o que corresponde em termos percentuais a 25,18\% em um ano, seguindo a tendência de expansão correlata ao período de vigência do Reuni, e que detectamos como recorrente nas cinco IFES com maior oferta de vagas no Brasil entre 2007 a 2017.

Conforme visto mediante o exame do gráfico 5, há inegavelmente uma expansão nas vagas ofertadas e, com isso, torna-se necessário comparar em que medida ocorreu aumento do corpo docente durante o período 2007 a 2017, de modo a compreender como se deu a expansão na Educação Superior decorrente do Reuni. Assim, na próxima seção, analisamos os dados relativos ao corpo docente (em especial no que se refere aos concursados) das maiores IFES do país em número de alunos, estratificando tais dados por Região, de 
modo a compreender outro aspecto do Reuni: seu caráter de política nacional de reestruturação e expansão no que diz respeito à democratização deste nível da educação.

\section{REUNI E OS IMPACTOS NO CORPO DOCENTE DAS IFES POR REGIÃO DO PAÍS}

Nesta seção, pretendemos realizar uma análise de dados gráficos de uma série histórica, referentes ao período do Reuni e seus desdobramentos, com especial atenção aos indicadores relativos ao corpo docente de modo a mostrar a evolução quantitativa e a mudança no padrão formativo com a entrada de professores nas IFES.

Estratificamos a análise por região, usando como critério analítico 03 ou 04 das maiores IFES de cada região, descrevendo os dados referentes à variação quantitativa do seu corpo docente. Deve ser salientado o fato de que os dados a que nos referimos dizem respeito somente aos docentes concursados, não incluindo os contratados ou substitutos nos números de cada IFES.

\section{Gráfico 8 - Docentes das IFES da Região Norte.}

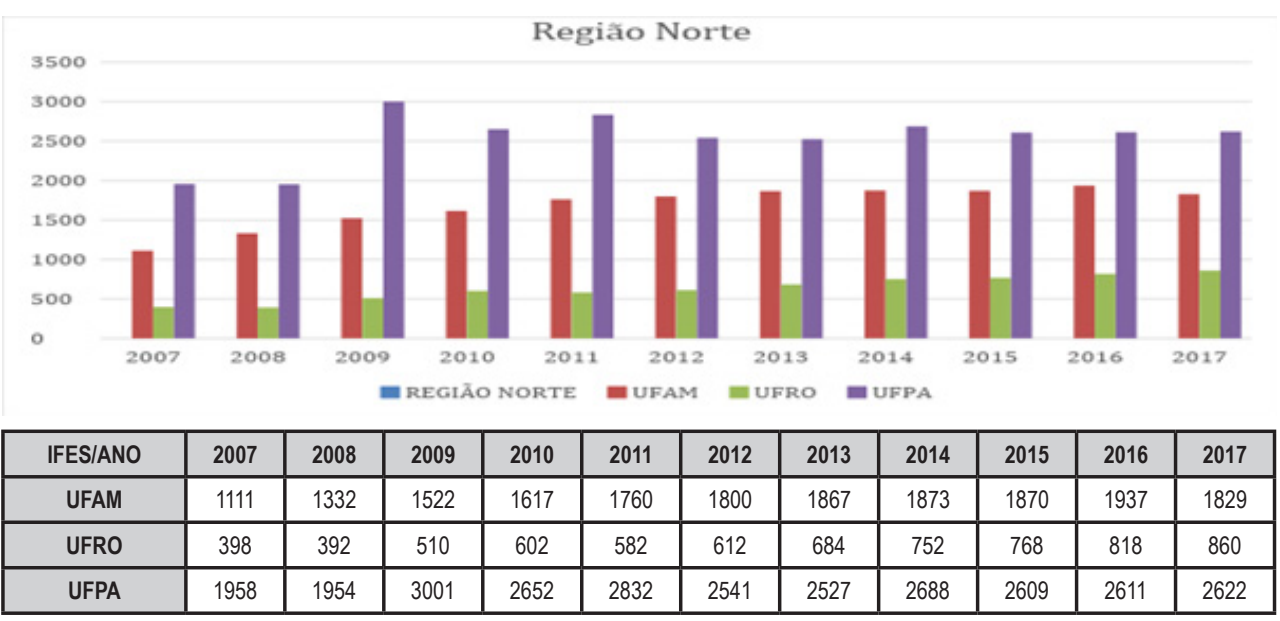

Fonte: Elaboração dos autores.

De 2007 a 2013, foi observada, na Universidade Federal do Amazonas (UFAM), uma expansão do número de docentes de aproximadamente $60 \%$ do seu quadro, aumentando de 1.111 profissionais em 2007 para 1.867 em 2013, 
crescimento que se manteve nos anos seguintes à finalização do programa, chegando a 1.873 docentes em 2014 e voltando a cair em 2017, já passados quatro anos de finalização do programa e já não sendo mais possível sentir efeitos.

Passando a análise para a Universidade Federal de Rondônia (UFRO), observamos que, durante o período do Reuni, o crescimento chegou a 41,9\% do quadro de profissionais, partindo de 398 professores em 2007 para 684 em 2013, crescimento que se manteve nos anos seguintes, chegando a 752 profissionais em 2014 e 860 em 2017, um acréscimo de aproximadamente 12,6\% dos docentes mesmo após a finalização do programa.

Das universidades da região norte, a Universidade Federal do Pará (UFPA) foi a instituição que apresentou um crescimento mais discreto do quadro de docentes, variando de 1.958 profissionais em 2007 para 2.527 em 2013, um crescimento de 22,5\%. Já nos anos posteriores ao Reuni, a UFPA registrou o aumento para 2.688 professores em 2014, em seguida caindo para $2.622 \mathrm{em} \mathrm{2017,}$ decréscimo também discreto de $2,5 \%$ do total de docentes.

Examinando dados da região norte, observamos duas tendências. A primeira é que todas as IFES analisadas apresentaram uma expansão significativa do quadro de docentes durante o período do Reuni, com até $60 \%$ de aumento do quadro de profissionais. A segunda é ocorrida posteriormente à finalização do programa, onde constatamos que, das IFES da região norte, somente a UFRO manteve o crescimento no número de docentes, enquanto a UFAM e a UFPA, que respondem por número maior de docentes dos quadros das instituições, apresentaram uma diminuição deste indicador. Portanto, na região norte, o Reuni trouxe um impacto muito positivo ao incremento do número de cargos de docentes e, por outro lado, sua finalização também se refletiu no decréscimo de contratações de substitutos. 


\section{Gráfico 9 - Docentes das IFES da Região Sul.}

\begin{tabular}{l} 
Região Sul \\
\begin{tabular}{|l|l|l|l|l|l|l|l|l|l|l|l|}
3500 \\
3000 \\
2500 \\
2000 \\
1500 \\
1000 \\
500
\end{tabular} \\
\hline
\end{tabular}

Fonte: Elaboração dos autores.

A Universidade Federal do Rio Grande do Sul (UFRGS) registrou um aumento de $5,8 \%$ do seu quadro de docentes no período do Reuni, saindo de 2.461 professores em 2007 para 2.612 docentes em 2013. Nos anos subsequentes, o crescimento foi mantido, registrando, em 2014, o aumento para 2.749 docentes e, em 2017, chegando a 2.881. O Reuni e seus reflexos foram responsáveis nesta instituição por um crescimento de $17 \%$ em seu quadro docente.

A Universidade Federal de Santa Catarina (UFSC) apresentou em 2007 o número de docentes de 1.985; em 2013 o número era de 2.463, o que significou um crescimento de 19,4\% durante o período do Reuni. Já nos anos subsequentes, com os desdobramentos do programa, saltou para 2.478 profissionais em 2014 e, em 2017, para 2.617, um crescimento de 5,31\% no período posterior ao Reuni.

$\mathrm{Na}$ Universidade Federal do Paraná (UFPR), durante o programa, observou-se a variação de docentes de 2.026 em 2007 para 2.335 em 2013, um crescimento de 13,3\% do total de docentes. Posteriormente, em 2014, registrouse 2.415 docentes, subindo para 2.418 em 2017, uma tendência que mostra relativa estagnação da contratação de docentes nos anos posteriores ao programa.

Analisando os dados da região sul, nota-se o expressivo incremento no número de docentes das suas três maiores IFES. Temos igualmente uma tendência de crescimento observado em todas as IFES desta região no período de 2014 a 2017, subsequente ao Reuni. 


\section{Gráfico 10 - Docentes das IFES da Região Sudeste.}

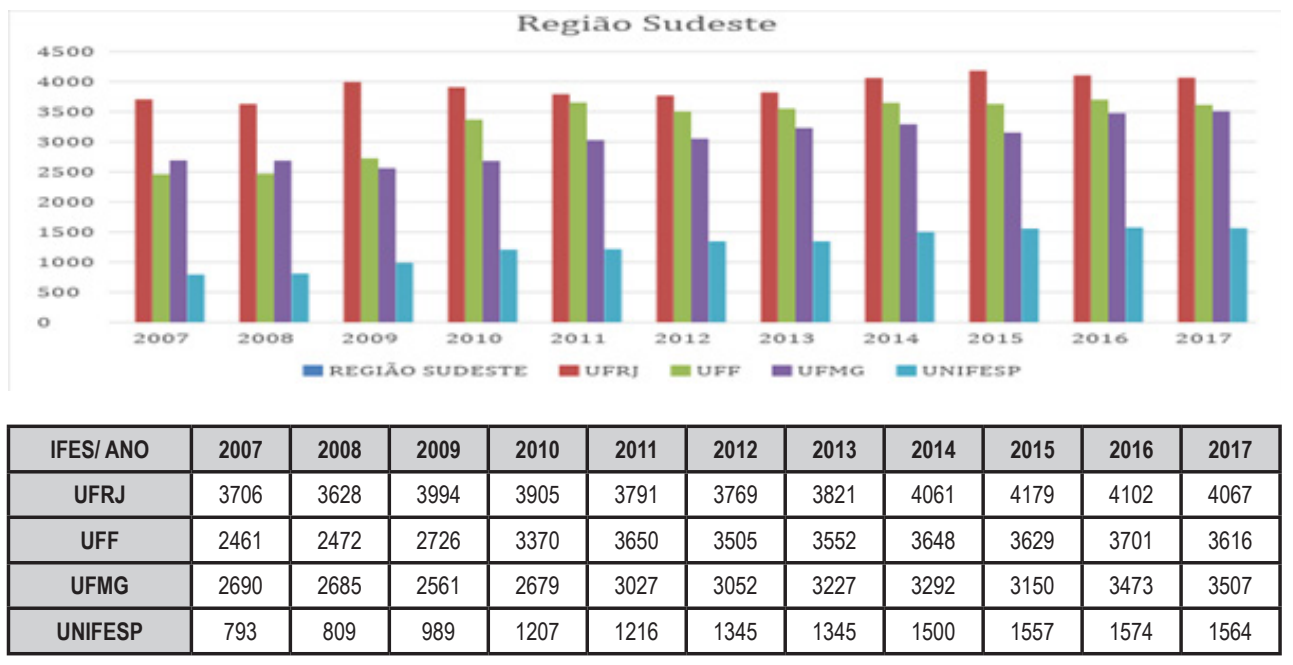

Fonte: Elaboração dos autores.

Na Universidade Federal do Rio de Janeiro (UFRJ), o número de docentes, em 2007, correspondia a 3.706, chegando a 3.821 em 2013, um aumento de aproximadamente 3\%. Já em 2014, o número chegou a 4.061 profissionais e, em 2017, a 4.067, um incremento pouco significativo de aproximadamente $0,014 \%$, mostrando pouco crescimento no número de docentes.

Na Universidade Federal Fluminense (UFF), havia, em 2007, um total de 2.461 docentes, chegando a 3.552 em 2013, um crescimento de 30,7\%, que pode ser (ao menos em parte) atribuído ao Reuni. No período posterior ao programa, foi registrado, em 2014, o número de 3.648 docentes e 3.618 em 2017, configurando uma retração de $0,82 \%$ no número de professores.

$\mathrm{Na}$ Universidade Federal de Minas Gerais (UFMG), foi registrado um aumento de $16,64 \%$ no quadro docente durante o período do Reuni, passando de 2.690 professores em 2007 para 3.227 em 2013. O crescimento permaneceu no período posterior ao programa, indo de 3.292 profissionais em 2014 para 3.527 em 2017, um acréscimo de 8,44\%.

A Universidade Federal de São Paulo (UNIFESP) apresentou, durante o período do Reuni, um crescimento de aproximadamente $41 \%$, registrando, no ano de 2007, um total de 793 docentes e, em 2013, crescendo para 1.345 profissionais. No período posterior ao programa, foi mantido o crescimento, indo em 2014 para o total de 1.500 docentes e, em 2017, para 1.564, um crescimento de 4,26\% no período. 
Os dados da região sudeste apontam para um crescimento contínuo do número de docentes, sendo notável em todas as IFES analisadas durante o período do Reuni o incremento deste indicador, em termos relativos e absolutos.

\section{Gráfico 11 - Docentes das IFES da Região Nordeste.}

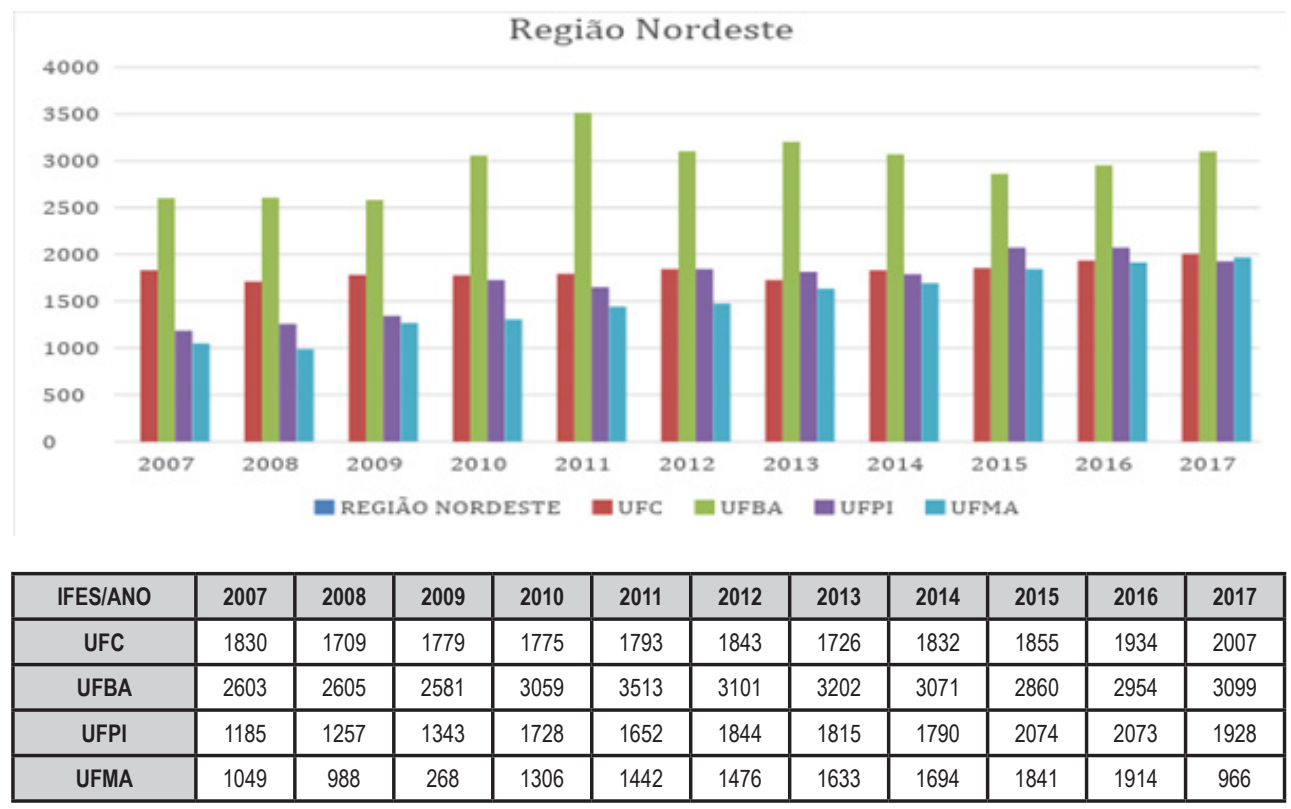

Fonte: Elaboração dos autores.

$\mathrm{Na}$ Universidade Federal do Ceará (UFC), o número de professores, em 2007, correspondia ao total de 1.830 e, no final do programa, este número passou para 1.726 , apontando um decréscimo de $6,02 \%$ no indicador ora examinado. No período posterior ao Reuni (2014 a 2017) os números de docentes subiram para

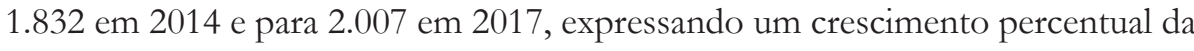
ordem de $8,71 \%$.

A Universidade Federal da Bahia (UFBA) apresentou um crescimento de 23,01\% no quadro de docentes durante a vigência do Reuni, partindo em 2007 de um total de 2.603 professores e subindo para 3.202 em 2013. Já no período posterior ao programa, foi registrada inicialmente uma queda no quadro docente, caindo para 3.071 profissionais em 2014 e apresentando uma pequena recuperação no ano de 2017, chegando a 3.099 profissionais. Cabe mencionar que, entre 2013 (fim da vigência do Reuni) e 2014 (passado um ano do fim do Reuni), houve uma retração de 131 docentes, o que em termos percentuais corresponde a um decréscimo de 4,09\% neste quantitativo um ano após o encerramento do Reuni. 
A Universidade Federal do Piaú (UFPI) apresentou um crescimento de $35,9 \%$ do número de docentes durante os anos de desenvolvimento do programa, indo de 1.185 profissionais em 2007 para 1.815 no ano de 2013. Nos anos posteriores ao fim do programa e ainda sob os efeitos do mesmo, foi registrada, em 2014, uma pequena queda no quadro docente, indo para 1.790, e voltando a crescer novamente em 2017 com 1.928 profissionais.

No que se refere à Universidade Federal do Maranhão (UFMA), os números absolutos e relativos ao período de vigência do Reuni indicam um total de 1.049 professores em 2007 e 1.633 em 2013. A variação observada denota que durante a vigência do programa houve um crescimento de 35,76\%. Em 2014, o total de docentes desta IFES era de 1.694, enquanto em 2017 alcançava o patamar de 1.996 docentes. Tais dados expressam um crescimento percentual de 15,13\% no período posterior ao programa. Comparando os dois períodos (durante e após o Reuni) é possível inferir que nesta IFES houve um crescimento 20,63\% maior durante o Reuni.

Com exceção da Universidade Federal do Ceará (UFC), a região nordeste como um todo apresentou um crescimento contínuo do quadro de professores durante os anos de desenvolvimento do programa, assim como nos anos subsequentes. Igualmente merece destaque a Universidade Federal da Bahia (UFBA), cujos impactos do Reuni no crescimento do número de docentes se mostrou mais visível no período posterior ao programa quando (conforme foi explicitado anteriormente) houve uma retração de 4,09\% do quantitativo destes em 2014.

\section{Gráfico 12 - Docentes das IFES da Região Centro-Oeste.}

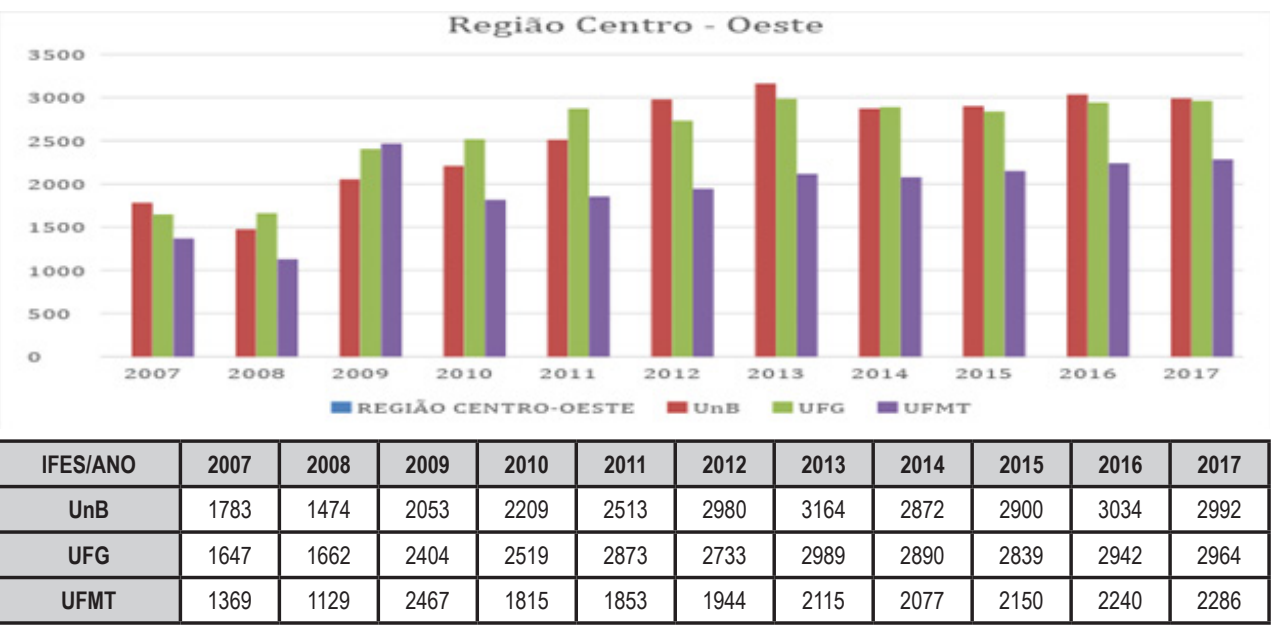

Fonte: Elaboração dos autores. 
$\mathrm{Na}$ região centro-oeste, os dados indicam igualmente um crescimento contínuo no número de docentes ao longo de toda a série histórica, sendo mais intenso durante o período do Reuni. Algumas instituições, como a Universidade Federal de Mato Grosso (UFMT), apresentaram uma retração no período posterior ao programa em relação a instituições da mesma região, como a Universidade de Brasília (UnB) e a Universidade Federal de Goiás (UFG).

$\mathrm{Na} \mathrm{UnB}$ os docentes compunham um total de 1.783 profissionais do quadro em 2007, subindo para 3.164 em 2013, um crescimento de 43,64\%. Já no período posterior ao programa, os números sofreram um decréscimo, indo para 2.872 professores em 2014 e apresentando um pequeno aumento em 2017, indo para 2.992 o número de docentes.

Em relação à UFG, os números mostram que em 2007 havia 1.647 professores e que em 2013 este número chegou a 2.989, um crescimento de $44,89 \%$ do quadro de docentes da instituição. No período posterior ao programa, houve uma queda nos números, indo a 2.890 em 2014 e voltando a crescer em 2017, com 2.964 profissionais, um crescimento de 2,49\%.

A UFMT apresentou, durante o Reuni, um crescimento de $35,27 \%$ do seu quadro de docentes, indo de 1.369 docentes concursados em 2007 para 2.115 em 2013. No período posterior ao programa, repetindo a tendência das demais IFES da região, houve um decréscimo do número de docentes, que foi a $2.077 \mathrm{em}$ 2014, voltando a subir em 2017 para 2.286 profissionais desta categoria.

\section{IMPACTOS DO REUNI NA RELAÇÃO DOCENTE/VAGA: UM EXAME DE QUATRO DAS CINCO MAIORES IFES EM NÚMERO DE ESTUDANTES QUANTO À ENTRADA DE DOCENTES}

Após a análise dos dados relativos à entrada de docentes nas maiores IFES de cada região do país, devem ser feitos alguns comentários. Os mesmos permitem que seja possível avaliar a lógica intrínseca à construção do objeto e das inferências provenientes de tal construção.

De modo geral, cabe reiterar nossa posição teórico-epistemológica, no sentido de que pressupomos que "os dados não falam por si" e que as correlações entre indicadores provenientes dos dados construídos permitem a realização de inferências que vão para além da aparência primeira, ou, se preferirmos, para além do obstáculo epistemológico da experiência primeira (Bachelard, 1974, p. 37).

Devido a essa premissa, entendemos que os dados referentes à matrícula de quatro das cinco IFES com maior número de vagas ofertadas (tal como apresentamos em seção anterior do trabalho) devem ser contrapostos aos dados de entrada de docentes, de maneira a compreender se a ampliação no quantitativo 
de vagas nas já mencionadas IFES (UFPI, UFF, UFRJ e UnB) se traduziu em ampliação proporcional do quadro de docentes. Tal seleção se justifica pelo fato de que os dados regionalizados, contemplados com as IFES apontadas naquele estudo comparativo (vide item 3 do artigo) e apresentados no mesmo (nenhuma das cinco maiores IFES se situava na Região Norte) correspondeu à ampliação proporcional do corpo docente nestes casos. Entendemos que tal correlação é importante na medida em que possibilita lançar um "olhar micro" (particular a cada instituição) de maneira a possibilitar correlações com o "olhar macro" (o quantitativo de IFES em nível nacional), o que entendemos ser fundamental para o complemento da análise desenvolvida com o exame da variação do corpo docente em nível regional.

Antes de iniciar a análise dos dados referidos, cabe ter em vista que o número de vagas por docente deve ser relativizado a partir dos seguintes fatores: 1) esse número não expressa o número total de matrículas das IFES (ver o item 2 deste artigo), podendo haver vagas ociosas, mas que não entram nesta mensuração; e 2) decorrente do primeiro ponto temos o fato de que o fluxo de estudantes (ingressantes e concluintes) não foi considerado neste artigo, porém sem dúvida (ao menos no que alude aos ingressantes) sofre influência da relação que se estabelece entre vagas ofertadas e docentes das IFES. Assim, após esta delimitação do alcance da combinação de indicadores (número de vagas por ano e número de docentes), passemos ao exame dos dados referentes às 04 IFES tomadas como objeto de análise amplificada.

No que tange à UFPI, ao justapormos os dados de série histórica relativos a número de vagas e docentes, temos em 2007: 4.915 vagas e 1.185 docentes concursados, o que expressa uma relação entre docentes por vaga cuja proporção é de aproximadamente 4 vagas por docente. Ao fim do Reuni (em 2014) temos 12.709 vagas e 1.790 docentes, o que traz uma proporção de aproximadamente $7(7,10)$ vagas por docente. No ano final da série histórica (2017) temos nesta IFES 1.928 docentes e 15.430 vagas, o que implica em uma relação de 8 vagas por docente. Este dado leva a crer que o aumento proporcional no número de vagas por docente dobra ao longo da série histórica, mantendo-se, porém, dentro de uma média compatível com a atividade docente (08 vagas por docente). Os dados relativos à quantidade de vagas por docente na UFPI levam-nos a crer que houve, ao longo da série histórica, uma ampliação de vagas por docente próxima de $100 \%$ (de quatro para oito vagas por docente), o que demonstra uma expansão quantitativa de grande monta no que se refere ao número de vagas, havendo, porém, uma expansão menor no número de docentes. 
Em relação à UFF, seguimos com a utilização de uma comparação de três momentos (anos) que entendemos como cruciais na periodização examinada (2007, 2014 e 2017). Assim, no que compete à relação entre vagas e docentes, chegamos às seguintes proporções: A) no primeiro momento temos: 4.798 docentes e 2.461 vagas, o que implica em uma relação de 1,94 (aproximadamente duas) vagas por docente; B) no segundo momento, os indicadores são os seguintes: 14.028 vagas e 3.648 docentes, o que redunda em uma proporção de 3,84 (aproximadamente quatro) vagas por docente; C) no terceiro momento a UFF possui o seguinte quantitativo de vagas e docentes: 14.205 vagas e 3.616 docentes, resultando numa proporção de 3,92 (aproximadamente quatro) vagas por docente. Examinando esses scores, depreendemos que logo após o Reuni (2014) ocorre uma expansão próxima de 100\% no quantitativo de vagas por docente, tendência esta que se mantém em 2017 com o quantitativo médio de 3,94 vagas por docente.

Ainda no que diz respeito à UFF, cabe tecer algumas considerações: 1) Após o Reuni, e até o fim da série histórica, o número de vagas por docentes se mantém com baixa variação, o que leva a confirmar a hipótese de que a expansão durante o Reuni se deu de modo constante e de que seus desdobramentos seguiram esta tendência até o fim da série histórica explorada (2007 a 2017), ao menos no que se refere ao número de vagas e docentes; 2) De acordo com o relatório de Gestão da UFF publicado no ano de 2016 (UFF, 2016), o perfil do corpo docente desta Universidade indicava, até o ano de 2015, um percentual de 85\% de Professores Doutores com Regime de 40h e Dedicação Exclusiva (DE). Estes dados são trazidos à baila como forma de exemplificar em nível "micro" o impacto do Reuni no que se refere às variações no corpo docente qualificado durante a série histórica analisada. Este detalhamento relativo à UFF se deu por sua característica singular no que diz respeito à interiorização, pois além de possuir diversos campi em sua sede em Niterói, a universidade está presente em mais treze municípios do RJ, além do Polo Avançado de Extensão em Oriximiná-PA. Tais características de capilaridade, somadas aos dados facilmente acessíveis no referido Relatório de Gestão, permitem avançar e compreender (ao menos a título de exemplo) como o Reuni impactou as IFES, não somente em relação à entrada de docentes, mas também quanto à qualificação destes e sua relação quantitativa com o corpo discente.

Com relação aos dados de série histórica, envolvendo docentes e vagas na UFRJ, temos os seguintes indicadores dispostos nos três momentos indicados anteriormente: A) em 2007 o número de vagas foi 6.625 e o de docentes 3.706 o que significa uma relação de 1,72 (aproximadamente duas vagas por docente); B) em 2014 o quantitativo de docentes e vagas era o seguinte: 11.097 vagas e 4.061 
docentes, o que gera uma proporção de 2,71 (aproximadamente três) vagas por docente); C) em 2017 temos os seguintes números de vagas e docentes: 11.199 vagas e 4.067 docentes, o que implica em 2,75 (aproximadamente três) vagas por docente. Assim como na UFF, é possível perceber que após o período do Reuni a ampliação da proporção de vagas por docente (que praticamente dobra se considerarmos o período que vai de 2007 a 2014) indicou uma tendência a se estabilizar até o fim da série histórica em 2017.

No que tange aos dados relativos a docentes e vagas na $\mathrm{UnB}$, temos os seguintes resultados: A) em 2007 havia 4.252 vagas e 1.783 docentes, perfazendo 2,3 vagas por docente; B) em 2014 o quantitativo de vagas e docentes era o seguinte: 9.775 vagas e 2.872 docentes, o que resulta em 3,4 vagas por docente; C) em 2017 as vagas eram 9.059 e o número de docentes 2.964 o que significa uma proporção de 3,05 vagas por docente. Conforme visto anteriormente a UnB segue a tendência no sentido de ampliar o número de vagas e docentes (ainda que com alguma desproporção) durante o Reuni, mantendo baixa variação de 2014 até o fim da série histórica em 2017.

Após a análise comparada dos indicadores de vagas e número de docentes entre 2007 e 2014 nas IFES escolhidas, como termos de comparação, foi possível perceber que a tendência de ampliação de vagas e docentes se concentrou nos anos do Reuni, gerando uma ampliação maior no número de vagas do que do número de docentes concursados. Isto corrobora (ainda que não demonstre completamente) a hipótese de que a ampliação do corpo docente está ligada ao aumento do número de estudantes nas IFES durante o Reuni, o que indica uma expansão da educação superior, brasileira, ao menos no que alude a estes indicadores.

\section{CONSIDERAÇÕES FINAIS}

Atestada a fidedignidade das fontes analisadas, cujos números apreendidos são de dados oficiais que foram auditados, podemos afirmar que houve impactos significativos nas IFES com a implantação do Reuni, e que seus efeitos se estenderam até 2017.

Conforme pudemos apresentar anteriormente, os programas de incentivo à pesquisa e pós-graduação, dentro de cada instituição ou através dos órgãos de fomento, foram fundamentais para estimular o crescimento dos cursos de pósgraduação dentro das instituições de ensino superior públicas. Conforme pudemos observar (em seção anterior deste trabalho), esses programas promoveram um aumento substancial do número de doutores e o crescimento dos programas 
de pós-graduação e das pesquisas nas universidades, com reflexo no número de publicações e produtos patenteados. Entendemos, portanto, que os impactos do Reuni foram positivos.

A análise dos dados consolidados de todas as regiões geográficas do Brasil mostrou que houve um incremento quantitativo e qualitativo na composição do corpo docente, com taxas de crescimento de até $60 \%$ em algumas regiões durante a vigência do prograna. No período posterior (2014 a 2017), é possível ainda identificar o impacto na maioria das IFES estudadas, as quais mantiveram o crescimento no número de professores, e, mesmo naquelas em que foi observada retração no número de docentes, o total de docentes foi igual ou maior que o observado no ano de 2007, quando o Reuni foi iniciado.

Assim sendo, após a análise dos dados oficiais, foi possível detectar que houve, isto sim, uma melhoria no ensino, na pesquisa, na pós-graduação, na extensão, na produção de trabalhos publicados e na produção de patentes (tal como assinalamos em seção anterior do artigo).

Em relação aos docentes das IFES, deve ser mencionado que houve uma redução substancial no número de professores substitutos, em contrapartida ao aumento do número de professores concursados, com títulos de doutores, o que reforça a tese de que o programa de reestruturação e expansão das universidades federais trouxe melhorias para a educação superior brasileira, em especial no que tange a seu corpo docente, o que pode ser constatado mediante consulta ao censo da educação superior nos anos que vão de 2007 a 2017.

À guisa de conclusão, cabe indicar que entendemos que uma pesquisa não apresenta conclusões definitivas, podendo sempre ser melhorada quando existem aspectos não abordados (ou abordados sob outra perspectiva). Assim, indicamos alguns elementos que podem ser mais bem explorados em futuros artigos que se detenham sobre a temática explorada. Vamos a eles: 1) um estudo que trabalhe os dados de série histórica relativo aos servidores técnicoadministrativos das IFES durante o período de 2007 a 2017 seria importante complemento ao artigo que ora apresentamos; 2) seria necessário quantificar em cada IFES qual o percentual de professores doutores, de maneira a poder aferir de modo mais preciso os impactos do Reuni sobre a qualificação do corpo docente dessas instituições; 3) Em escala "micro", o desenvolvimento de estudos com indicadores quantitativos e qualitativos (como: número de egressos, corpo docente, concluintes e reprovados) poderia trazer incremento no conhecimento sobre os impactos do Reuni, no que se refere às IFES no Brasil durante o período delimitado no escopo temporal do presente trabalho (2007 a 2017). 


\section{REFERENCIAS}

ALVES-MAZZOTTI, A.J; GEWANDSZNADJER, F. O método nas Ciências Sociais e Naturais. Pioneira: Campinas, 1997 ( $2^{\mathrm{a}}$ ed.).

ANTUNES, V. V. Expansão e democratização universitária: a implementação do REUNI na Universidade Federal do Rio de Janeiro. Revista Habitus: Revista da Graduação em Ciências Sociais do IFCS/UFRJ, Rio de Janeiro, v. 14, n. 1, p. 91-99, 10 de nov. 2016.

BACHELARD, G. O Racionalismo Aplicado. Jorge Zahar: Rio de Janeiro, 1974.

BACHELARD, G. A Formação do Espírito Científico: contribuição para uma psicanálise do conbecimento, Contraponto: Rio de Janeiro, 1996.

BRASIL. Decreto $\mathbf{n}^{\mathbf{0}} \mathbf{6 0 9 4}$ de $\mathbf{2 4}$ de abril de 2007. Dispõe sobre a implementação do Plano de Metas Compromisso Todos pela Educação, pela União Federal, em regime de colaboração com Municípios, Distrito Federal e Estados, e a participação das famílias e da comunidade, mediante programas e ações de assistência técnica e financeira, visando a mobilização social pela melhoria da qualidade da educação básica. Diário Oficial da União, Poder Executivo, Brasília, DF, 25 abr. 2007-a, p. 36.

BRASIL. Decreto $\mathbf{n}^{\mathbf{0}} \mathbf{6 . 0 9 6}$ de 24 de abril de 2007. Institui o Programa de Apoio a Planos de Reestruturação e Expansão das Universidades Federais - REUNI. Diário Oficial da União, Poder Executivo, Brasília, DF, 25 abr. 2007-b, p.59.

CAMPOS, I.M.V., CARVALHO, C.H.A. Análise do Reuni como política pública de financiamento da expansão da educação superior, Revista Forges, v. 2, n.2, dez. 2015, p. 1-13.

COSTA, D.M.C. et al., Financiamento Público e Expansão da Educação Superior Federal no Brasil: O REUNI e as perspectivas para o REUNI 2. Revista GUAL, Florianópolis, vol. 6, n. 1, p. 106-127, jan. 2013.

DOURADO, L.F. Reforma do Estado e as políticas para a educação superior nos anos 90. Educação e Sociedade - n. 80. Campinas, SP: Cedes, 2002. 
DOURADO, L.F. Lula e a educação superior pública no Brasil. Jornal O Popular. 07.01.2003 (Seção Opinião).

INEP/MEC. Censo da Educação Superior 2017: resumo técnico. Brasília: Inep, 2018.

INEP/MEC. Censo da Educação Superior 2018: sinopses estatísticas. Brasília: Inep, 2018. Disponível em: http://portal.mec.gov.br/docman/setembro-2018pdf/97041-apresentac-a-o-censo-superior-u-ltimo/file. Acesso em 25/03/2020.

LEHER, R. Educação superior minimalista: a educação que convém ao capital no capitalismo dependente. Site Insurgência, Rio de Janeiro. 2012. Disponível em: http:/ / www.insurgencia.org/educacao-superior-minimalista-a-educacao-queconvem-ao-capital-no-capitalismo-dependente/. Acesso em: 02 abr. 2019.

MANCEBO, D; BESSA, L. REUNI: heteronomia e precarização da universidade e do trabalho docente. Educação \& Realidade. Vol. 34, n. 1, jan-abr, pp. 49-64, Universidade Federal do Rio grande do Sul, Porto Alegre, Brasil, 2009.

MAUÉS, O. A reconfiguração do trabalho docente na educação superior. Educar em Revista, Editora UFPR. Curitiba, Brasil, n. especial 1, p. 141-160, 2010.

PAULA, C. H. A influência do REUNI sobre o desempenho das Instituições Federais de Ensino Superior. Dissertação (Mestrado em Administração). UFV, Viçosa. 2018.

SANTOS, P. S.M.B. Guia Prático da Política Educacional no Brasil: ações, planos, programas e impactos. São Paulo: Cengage, 2014 ( $2^{\mathrm{a}}$ ed.).

SOUZA, C.D. et al. Impacto do Programa de Apoio a Planos de Reestruturação e Expansão das Universidades Federais Brasileiras (REUNI) na atividade investigativa: crescimento, qualidade e internacionalização. Revista Em Questão, Porto Alegre, v. 21, n. 3, p. 336-367, set/dez. 2015. 


\section{Roberto de Souza Salles}

Doutor em Sanidade Animal pela UFRRJ. Professor Titular - Universidade Federal Fluminense. Email: souzasallesroberto@gmail.com

\section{Eduardo Faerstein}

Doutor em Epidemiologia na Johns Hopkins University, EUA. Professor Associado, Instituto de Medicina Social - Universidade Estadual do Rio de Janeiro. Email: efaerstein@gmail.com

\section{Mario Roberto Dal Poz}

Doutor em Saúde Publica (FIOCRUZ). Professor Titular, Instituto de Medicina Social, Universidade do Estado do Rio de Janeiro, Brasil. E-mail: dalpozm@ uerj.br

\section{Pablo Silva Machado Bispo dos Santos}

Doutor em Educação pela PUC-Rio. Professor Associado do Departamento de Sociedade, Educação e Conhecimento - Universidade Federal Fluminense. Email: pablobispo@id.uff.br 